\title{
The deformability of short pillars in various loading options and external composite reinforcement
}

\author{
Petr Polskoy ${ }^{1}$, Sergey Georgiev ${ }^{1}$, Viktor Muradyan ${ }^{1, *}$, and Aleksandr Shilov ${ }^{1}$ \\ ${ }^{1}$ Don State Technical University, Rostov-on-Don, Russia
}

\begin{abstract}
The test results on deformation and rigidity of short compressed reinforced concrete pillars with various types of external transverse and longitudinal composite reinforcement are given. The samples from heavy concrete with design strength class B30-35 were tested, having the same cross-section 250x125 (h) mm and length $1200 \mathrm{~mm}$ with flexibility $\lambda \mathrm{h}=10$. The pillars were reinforced with $4 \varnothing 12 \mathrm{~A} 500$ in the longitudinal direction and with tied clamps Ø6B500, installed with the step of $180 \mathrm{~mm}$ - in the transverse direction. The purpose of the experiment was to determine the effect of the rigidity of reinforced elements on the deformability of short experimental samples. It was necessary to determine how the eccentricity of the load application influences on the variation in the rigidity of the reinforced elements. The purpose was also to obtain data on the deformability of pillars loaded with small eccentricities, i.e. when $\mathrm{e}_{0}=$ $0.16 \mathrm{~h}$. It was found that the most effective type for short pillars reinforcement is a three-layer holder, which has maximum rigidity and minimal deformability. However, its efficiency gradually decreases when the eccentricity of the load application increases.
\end{abstract}

\section{Introduction}

Despite the fact that reinforced concrete for the next 20-25 years is still the main type of building materials, we cannot affirm that the theory and practice of its application will remain unchanged. This is due to the fact that with the increase in construction volumes, at the same time the technology of production of building materials and construction should improve, aimed at reducing labour costs, materials and energy intensity.

At the same time, it also concerns issues related to the increase in volume and costs for repair and restoration works that arise in the process of buildings and structures' reconstruction, as well as in structures' reinforcement.

The solution to these issues is impossible without the development of new, innovative materials and structures based on them.

The Department of Reinforced Concrete and Stone Structures at Don State Technical University is engaged in solving these issues during the last 10-15 years. First, it refers to the development and improvement of the calculation apparatus, which is based on a wide

\footnotetext{
* Corresponding author: muradyan2007@yandex.ru
} 
base of conducted experiments. It concerns the properties and design features of highstrength concrete [1-4].

Problems connected with the theory and practice of prestressed structures, for which the variable prestressing along the length of structures are urgent, are still being solved [5-7]. There is a special attention to the issues of using the composite materials in construction which has been developing in two areas. The first is the use of bars reinforcement as a working one, which is especially important for carbon fiber reinforced plastic having almost identical modulus of elasticity with steel [8-10]. The second is the use of composite external reinforcement for reinforced concrete structures. It is carried out in three directions. The bent elements reinforcement can be along the normal (1st) and oblique sections (2nd) directions [11-13]. The third direction is the reinforcement of compressed elements of different flexibility [14]; type of stressed-deformed state [15, 16] and options for transverse or longitudinal reinforcement [17].

\section{Research objectives and tasks}

As it is known, the growth of all newly designed and reinforced structures is performed in two groups of limit states, namely, in strength and deformation. Considering that for the structures reinforced with the use of composite materials, the experimental base in Russia is still limited, the calculations for these structures in the II group of limit states are very relevant, because much depends on the rigidity of reinforcement elements. In the first place, it refers to the compressed elements. The most common of them are short elements.

This paper considers the deformability of compressed columns with the flexibility $\lambda_{h}=10$ in various options of loading and reinforcement. The purpose of the study is the following:

- to determine the rigidity of the reinforcement elements effect on the deformability of short experimental samples;

- to determine the eccentricity of the load application effect on the change in the rigidity of the reinforcement elements;

- to obtain data on the deformability of pillars, with three values of eccentricity, in order to cover the entire spectrum of stressed-deformed state of the compressed elements. It is especially important to obtain these data at $\mathrm{e}_{0}=0.16 \mathrm{~h}$ (small eccentricities) because they are not stipulated in the normative documents.

\section{Materials and methods}

This article is devoted to the comparison of deformability of short compressed reinforced concrete elements with flexibility $\lambda_{h}=10$, reinforced by the range of options for external transverse, longitudinal and combined composite reinforcement and tested at three values of eccentricity of the load application at $\mathrm{e}_{0}=0 ; \mathrm{e}_{0}=2.0 \mathrm{~cm}(0.16 \mathrm{~h}) ; \mathrm{e}_{0}=4.0 \mathrm{~cm}(0.32 \mathrm{~h})$. It is under these loads that all types of stressed-deformed state of compressed elements are covered. This article is a continuation of the already mentioned article [17], where the strength indicators of short pillars for various varied data are analyzed in detail.

The16 reinforced concrete samples were tested with the section of $250 \times 125(\mathrm{~h}) \mathrm{mm}$ and the length of $1200 \mathrm{~mm}$, made of heavy concrete with a design strength class B30-35. The characteristics of materials, including composite materials, the structure of frameworks and the method of experimental samples reinforcement are detailed in the works [18-20]. Here, to understand the object of research, we briefly note the following. The longitudinal reinforcement of all the pillars was the same and consisted of 4Ø12A500. The tied cross 
clamps were made of wire reinforcement with Ø6B500 and installed with the step of 180 $\mathrm{mm}$.

All the experimental samples, depending on the eccentricity of the load application $\left(\mathrm{e}_{0}\right)$, were divided into three series. The pillars of "A" series were tested with the axial eccentricity of the load application $\mathrm{e}_{0}=0$, in the "B" series the load was applied with eccentricity $\mathrm{e}_{0}=2.0 \mathrm{~cm}(0.16 \mathrm{~h})$, and in the "C" series with $\mathrm{e}_{0}=4.0 \mathrm{~cm}(32 \mathrm{~h})$.

\section{Results of research}

The 9 variants of composite reinforcement were investigated. External transverse reinforcement was made of three-layer closed clamps (X1; X2; X3; X5 and X6) with various width (50 and $250 \mathrm{~mm}$ ); and with the step in axes equal to 115,145 and $190 \mathrm{~mm}$, including the full holder. Individual pillars had longitudinal reinforcement in the form of strips (laminate) with the width of $50 \mathrm{~mm}$ and thickness of $1.2 \mathrm{~mm}$. It was carried out together with the transverse clamps. In addition, at the ends of the pillars near the steel headstocks, $100 \mathrm{~mm}$ clamps were glued, which served as anchors.

The characteristics of all experimental samples, indicating the options for their reinforcement by composite materials and also the strength characteristics of all pillars are given in Table 1.

The evaluation of deformability of standard and reinforced experimental samples, when the magnitude of the load and the eccentricities of its application changes, is performed on the basis of making the schedule of the movement change or the sag $(\Delta \cdot f)$ of pillars. These graphs, shown in Figures 1-3, were built from the results of deflectometer's processing, installed on the samples and recorded in the logs during testing of the samples. For convenience of the analysis, in Table 1, simultaneously with the pillars' call number, which reflects the options of reinforcement, the serial number of the experimental samples is shown, which appears in the text.

Considering the graphs in Figures 1-3 and using the direct comparison method for the experiment results, we can note the following:

- in the whole range of loads (from the beginning of loading to the stage, preceded the destruction), the limit deformations of standard pillars turned out to be smaller in comparison with the deformations of the reinforced samples, because their strength is much lower. The exception to this is only the individual reinforced samples, in which the strength of the concrete proved to be lower than those of the standard.

Table 1. Characteristic of short $(\lambda \mathrm{h}=10)$ reinforced pillars and test results with various axial eccentricity values $\mathrm{e}$.

\begin{tabular}{|c|c|c|c|c|c|c|}
\hline \multirow{2}{*}{$\begin{array}{c}\text { The } \\
\text { characteristic } \\
\text { of } \\
\text { experimental } \\
\text { samples }\end{array}$} & \multirow[b]{2}{*}{$\begin{array}{c}\text { Serial } \\
\text { number }\end{array}$} & \multirow{2}{*}{$\begin{array}{c}\text { Pillars' } \\
\text { call } \\
\text { number }\end{array}$} & \multirow[b]{2}{*}{$\begin{array}{l}\text { Concrete } \\
\text { class } B\end{array}$} & \multirow[b]{2}{*}{ Reinforcement option } & \multicolumn{2}{|c|}{$\begin{array}{l}\text { Experimental } \\
\text { values }\end{array}$} \\
\hline & & & & & $\begin{array}{l}\text { Strength, } \\
\text { kN } \\
N_{s} ; N_{s, f}\end{array}$ & $\begin{array}{l}\text { Sags } \\
f^{\text {exp }}, \\
\text { mm }\end{array}$ \\
\hline 1 & 2 & 3 & 4 & 5 & 6 & 7 \\
\hline \multirow{4}{*}{ 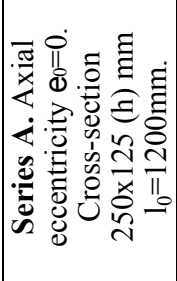 } & 1 & $\mathrm{AK}$ & 33,2 & Standard & 1150 & 1,165 \\
\hline & 2 & $\begin{array}{c}\text { AKU- } \\
\mathrm{X}_{1} \\
\end{array}$ & 30,0 & $b_{f}=50 \mathrm{~mm} ; s_{f}=190 \mathrm{~mm} ; \mathrm{s}=140 \mathrm{~mm}$ & 1190,5 & 0,4 \\
\hline & 3 & $\begin{array}{c}\text { AKU- } \\
\mathrm{X}_{6}\end{array}$ & 39,3 & $b_{f}=50 \mathrm{~mm} ; s_{f}=115 \mathrm{~mm} ; \mathrm{s}=65 \mathrm{~mm}$ & 1600 & 2,56 \\
\hline & 4 & $\begin{array}{c}\text { AKU- } \\
\mathrm{X}_{5}\end{array}$ & 30,1 & $b_{f}=720 \mathrm{~mm}$ ( Holder along the whole & 1625 & 0,7 \\
\hline
\end{tabular}




\begin{tabular}{|c|c|c|c|c|c|c|}
\hline & & & & length) & & \\
\hline & 5 & $\begin{array}{l}\text { AKU- } \\
X_{1} L_{\mu} \\
\end{array}$ & 31,8 & $b_{f}=50 \mathrm{~mm} ; s_{f}=190 \mathrm{~mm} ; \mathrm{s}=140 \mathrm{~mm} ; 4 L_{c}$ & 1100 & 0,71 \\
\hline & 6 & $\begin{array}{l}\text { AKU- } \\
X_{1} R_{\text {L }}\end{array}$ & 30,1 & $b_{f}=50 \mathrm{~mm} ; s_{f}=190 \mathrm{~mm} ; s=140 \mathrm{~mm} ; 4 \varnothing 8 \mathrm{R}_{\mathrm{c}}$ & 1379 & 1,82 \\
\hline & 7 & BК & 30,3 & Standard & 592,5 & 5,3 \\
\hline $\begin{array}{l}\text { Uे } \\
\dot{g} \\
\dot{g}\end{array}$ & 8 & $\begin{array}{c}\text { BKU- } \\
\mathrm{X}_{1}\end{array}$ & 30,0 & $b_{f}=50 \mathrm{~mm} ; s_{f}=190 \mathrm{~mm} ; \mathrm{s}=140 \mathrm{~mm}$ & 778,9 & 7,28 \\
\hline$\pi_{0}=$ & 9 & $\begin{array}{c}\text { BKU- } \\
\mathrm{X}_{2} \\
\end{array}$ & 30,3 & $b_{f}=50 \mathrm{~mm} ; s_{f}=145 \mathrm{~mm} ; \mathrm{s}=95 \mathrm{~mm}$ & 794,7 & 6,5 \\
\hline : & 10 & $\begin{array}{c}\mathrm{UKY}- \\
\mathrm{X}_{5}\end{array}$ & 32,4 & $\begin{array}{l}b_{f}=720 \mathrm{~mm} \text { (Holder along the whole } \\
\text { length) }\end{array}$ & 844,0 & 7,6 \\
\hline 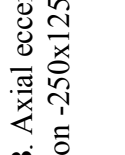 & 11 & $\begin{array}{l}\mathrm{BKU}- \\
\mathrm{X}_{2} \mathrm{Lc}\end{array}$ & 32,4 & $\begin{array}{l}b_{f}=50 \mathrm{~mm} ; s_{f}=145 \mathrm{~mm} ; s=95 \mathrm{~mm} \\
\text { 2-a of carbonlaminate in compressed zone: } \\
b=50 \mathrm{~mm} ; t=1,4 \mathrm{~mm}\end{array}$ & 800,0 & 6,3 \\
\hline 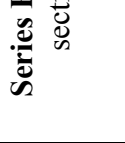 & 12 & $\begin{array}{l}\text { BKU- } \\
X_{1} L p\end{array}$ & 31,8 & $\begin{array}{l}b_{f}=50 \mathrm{~mm} ; s_{f}=190 \mathrm{~mm} ; s=140 \mathrm{~mm} \\
\text { 2-a of carbonlaminate in tensile zone: } \\
b=50 \mathrm{~mm} ; t=1,4 \mathrm{~mm}\end{array}$ & 700,0 & 11,4 \\
\hline$\approx$ & 13 & СК & 33,2 & Standard & 422,2 & 9,15 \\
\hline 曾全 & 14 & $\begin{array}{l}\text { CKU- } \\
\mathrm{X}_{1}\end{array}$ & 33,2 & $b_{f}=50 \mathrm{~mm} ; s_{f}=190 \mathrm{~mm} ; s=140 \mathrm{~mm}$ & 482,5 & 10,2 \\
\hline 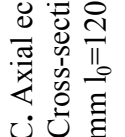 & 15 & $\begin{array}{l}\text { CKU- } \\
X_{1} L p\end{array}$ & 33,2 & $\begin{array}{l}b_{f}=50 \mathrm{~mm} ; s_{f}=145 \mathrm{~mm} ; s=95 \mathrm{~mm} \\
\text { 2-a of carbonlaminate in tensile zone } \\
b=50 \mathrm{~mm} ; t=1,4 \mathrm{~mm}\end{array}$ & 530 & 9,25 \\
\hline 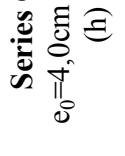 & 16 & $\begin{array}{l}\text { CKU- } \\
\mathrm{X}_{3} \mathrm{Lp}\end{array}$ & 39,4 & $\begin{array}{l}b_{f}=50 \mathrm{~mm} ; s_{f}=190 \mathrm{~mm} ; \text { Clamp in the center } \\
b_{f}=240 \mathrm{~mm} ; 2 \text {-a of carbonlaminate in tensile } \\
\text { zone: } b=50 \mathrm{~mm} ; t=1,4 \mathrm{~mm}\end{array}$ & 608 & 10,8 \\
\hline
\end{tabular}

Note: In Table 1 the following symbols are accepted: $b_{f}-$ the width of transverse composite reinforcement clamps or continuous holder; $s_{f}$ - the step of transverse clamps between the centers of their width; $s$ - the size of the gap between transverse clamps (the step of transverse clamps in the light). All the composite products were made of carboncloth with a single direction (MBRACE FIB CF 300/4900*300g* 100m) or carbonlaminate (lamellas) (MBRACE® LAM CF 210/2400*50*1.2*100m). Both types of carbon fiber reinforced plastic, as well as consumables - primer, putty and adhesive compounds were manufactured in Germany.

- The rigidity of all experimental samples, strengthened by external transverse or longitudinal (in combination with structural transverse) composite reinforcement was higher than that of the standard samples. It is displayed in increase (with respect to the horizontal axis) of inclination angle of all curves characterizing the relationship between sags - $f$ and the magnitude of the longitudinal load - N. It should also be noted that with the rigidity increase of the composite reinforcement option itself, the inclination angle of the curves also increases. There is no contradiction in it, since reinforced pillars have a higher 
strength, which is associated with the increase in the strength of concrete, which works in the presence of transverse clamps in confined conditions.

- With the increase in the eccentricity of the load application - $\mathrm{e}_{0}$, the inclination angle of all curves (standard and reinforced) relative to the horizontal axis also decreases. Short pillars with axial eccentricity $\mathrm{e}_{0}=0$ (Figure 1 ) have small displacements, which sometimes intersect the vertical axis in a zigzag pattern and start bending only outside the operational load level of 0.8. The limit values of these displacements are 0.4-0.6 $\mathrm{mm}$.

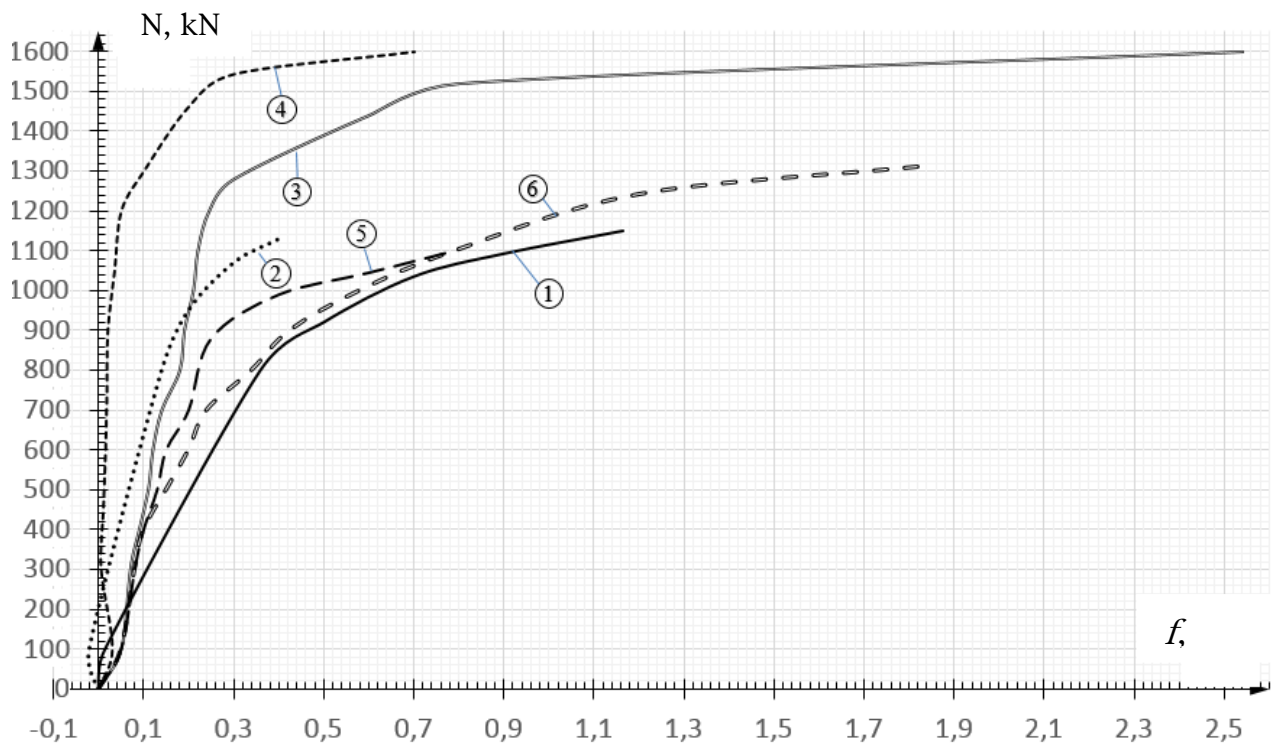

Fig. 1. Comparison of the experimental values of displacements of short $(\lambda \mathrm{h}=10)$ pillars depending on the load and options of composite reinforcement with axial eccentricity $\mathrm{e}_{0}=0$.

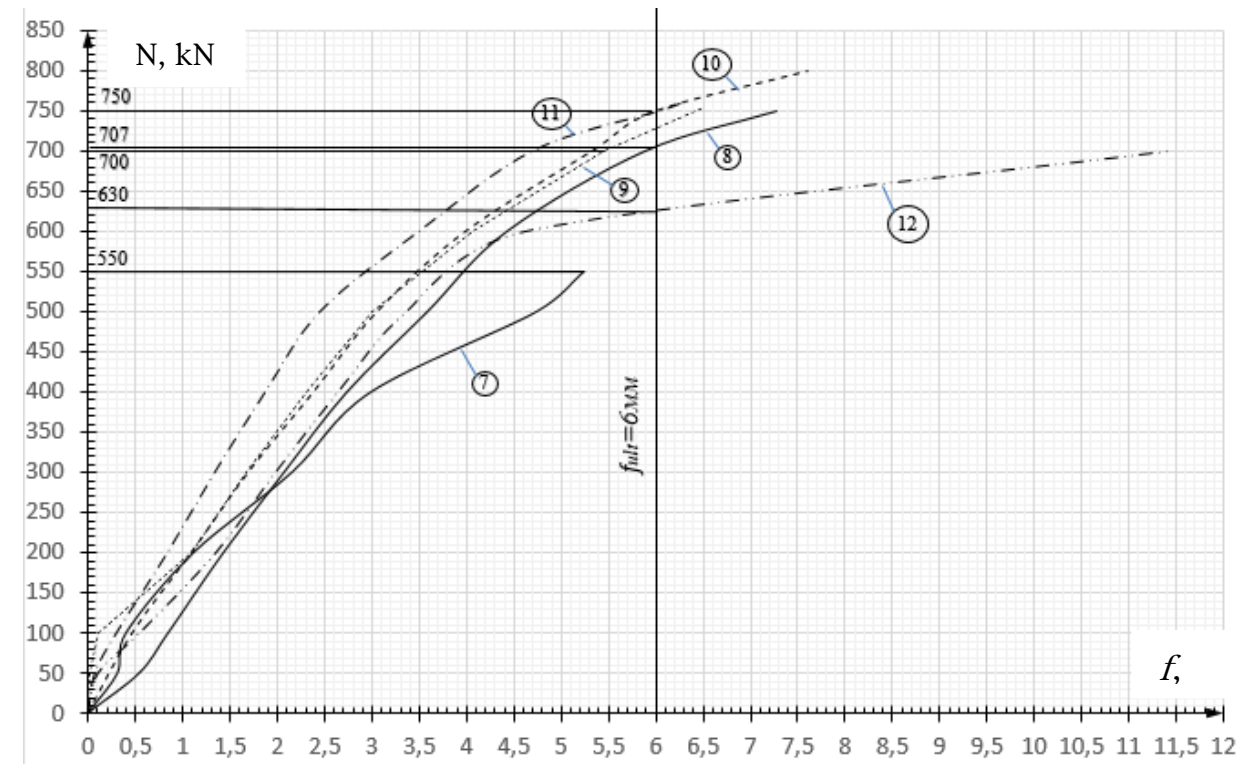

Fig. 2. Comparison of experimental values of sags of short $(\lambda \mathrm{h}=10)$ pillars depending on the load and options of composite reinforcement with axial eccentricity $\mathrm{e}_{0}=2,0 \mathrm{~cm}(0.16 \mathrm{~h})$. 


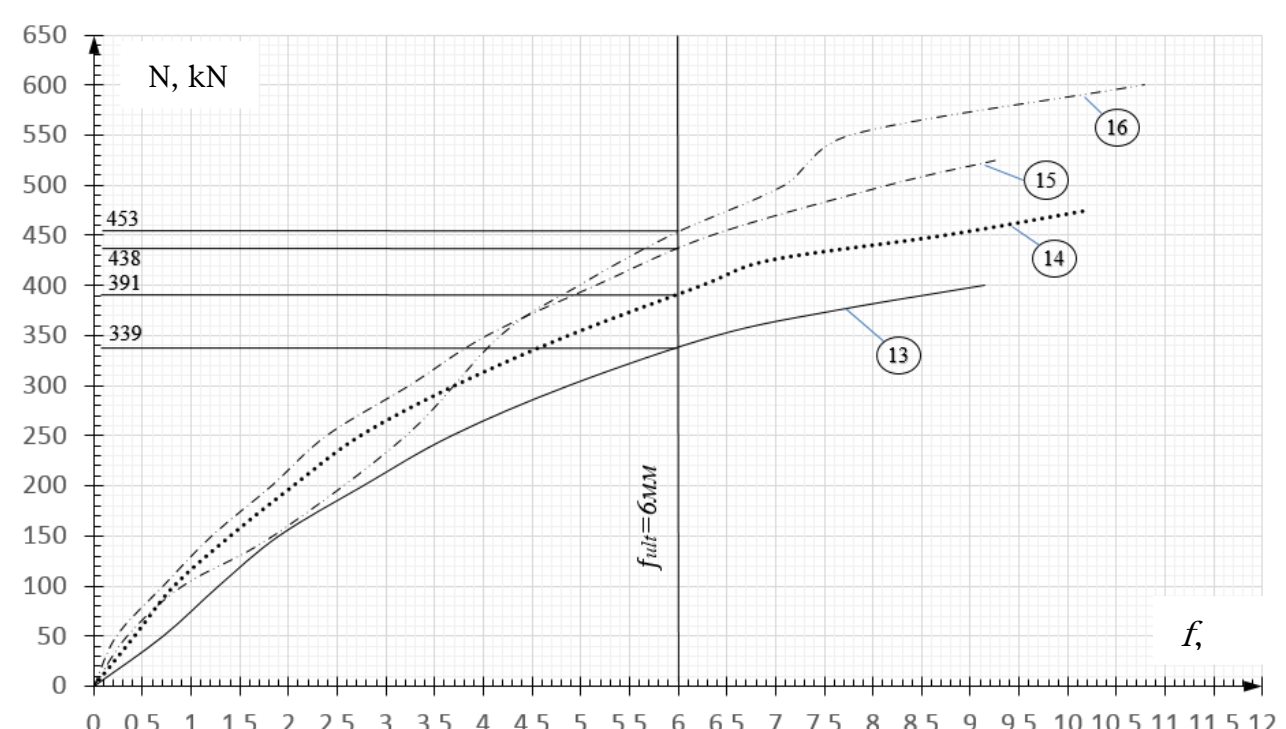

Fig. 3. Comparison of experimental values of sags of short $(\lambda \mathrm{h}=10)$ pillars depending on the load and options of composite reinforcement with axial eccentricity $\mathrm{e}_{0}=4,0 \mathrm{~cm}(0,32 \mathrm{~h})$.

- When the eccentricities of the load application are $e_{0}=2 \mathrm{~cm}$ and $e_{0}=4 \mathrm{~cm}$ (Fig. 2, 3), the above-mentioned regularity of the sags changes is preserved. However, the load levels at which standard and reinforced samples reach the maximum allowable sags $\left(f_{\text {ult }}=6,0 \mathrm{~mm}\right)$ decrease when the eccentricity increases.

- The short pillar (6), reinforced with round carbon fiber plastic bars of $8 \mathrm{~mm}$ in diameter, pasted into the longitudinal chase, despite the increase in the bearing capacity by almost $20 \%$, practically preserved the inclination angle of the curve, which runs practically parallel to the curve dependence of $\mathrm{f}^{\mathrm{exp}}-\mathrm{N}$ for the standard samples. It is connected, in our opinion, with the rigidity reduction of the pillar itself for making the slot for the installation of 4 composite bars.

- It is also important to note that, according to our experiments, the effectiveness of the transverse reinforcement of short pillars decreases a bit somewhat when the clamps are glued to longitudinal strips - the external reinforcement laminates. This is apparently due to the fact that concrete has a greater deformation in the transverse direction at the intersection of the longitudinal and transverse composite reinforcement.

\section{Conclusions}

1. The deformability of short compressed pillars is completely dependent on both the external composite reinforcement options and on the eccentricity of the load application. In this case, when the rigidity of reinforcement elements increases, the deformability of the samples decreases but when the axial eccentricity increases, $\mathrm{e}_{0}-$ also increases.

2. The magnitude of the limit deformations recorded before the destruction of the experimental samples is not a criterion for the effectiveness evaluation of various options of composite reinforcement, since for the reinforced samples it is usually higher in comparison with the standard samples. The actual criterion for this evaluation is the strength of the experimental samples at the maximum allowable sag value $\mathrm{f}_{\text {ult }}=6.0 \mathrm{~cm}$.

3. The criteria of the rigidity evaluation for various reinforcement options and, consequently, of the deformability of composite reinforcement evaluation, can be the 
inclination angle of the tangent to the point of origin. When this angle decreases, both the rigidity and strength of the reinforced pillars increase.

4. The smallest angle of inclination and the greatest strength, respectively, for $e_{0}=0 ; e_{0}=$ $2.0 \mathrm{~cm}(0.16 \mathrm{~h}) ; \mathrm{e}_{0}=4.0 \mathrm{~cm}(0.32 \mathrm{~h})$ showed that the samples reinforced with a solid holder and a holder with $65 \mathrm{~mm}$ wide gaps (reinforcement options X5 and X6); combined longitudinal reinforcement of the compressed zone with clamps X1 (option X1Lc); combined reinforcement by longitudinal reinforcement of the tensile side with clamps X1 or X3 (options X1Lp and X3Lp).

5. As the basic reinforcement option for short compressed elements loaded with small eccentricities, i.e, at e $0 \leq 0.16 \mathrm{~h}$, we can recommend a solid holder in the option X5. Note, in this case, that the efficiency of such a holder is 2 times lower compared to the central compression.

\section{References}

1. V. Muradyan, D. Mailyan, A. Lyapin, V. Chubarov, IOP Conference Series: Earth and Environmental Science 19. "Energy Management of Municipal Transportation Facilities and Transport, EMMFT 2017", p. 012032 (2017)

2. A.M. Mkrtchyan, D.R. Mailyan, Scientific Review, 11, $72-76$ (2013)

3. A.M. Mkrtchyan, V.N. Aksenov, D.R. Mailyan, A.M. Blyagoz, M.V. Smorgunova, New Technologies, 3, 135-143 (2013)

4. A.N. Davidyuk, D.R. Mailyan, G.V. Nesvetaev, Concrete Technologies, 1-2, 57-59 (2011)

5. D. Mailyan, V. Aksenov, N. Aksenov, Advances in Intelligent Systems and Computing, 692, 536-543 (2018)

6. D.R. Mailyan, R.L. Mailyan, M.V. Osipov, Concrete and reinforced concrete, 2, 18 (2002)

7. D.R. Mailyan, R.L. Mailyan, V.K. Khuranov, Proceedings of Higher Educational Institutions. Construction, 5, 4-11 (2004)

8. M. Khishmakh, D.R. Mailyan, P.P. Polskoy, A.M. Blyagoz, New Technologies, 4, 147-152 (2012)

9. D.R. Mailyan, P.P. Polskoy, Scientific Review, 12, 490-492 (2014)

10. P.P. Polskoy, D.R. Mailyan, Scientific Review, 12, 493-495 (2014)

11. P.P. Polskoy, D.R. Mailyan, Scientific Review, 12-3, 762-765 (2014)

12. P.P. Polskoy, D.R. Mailyan, A.A. Shilov, Z.F. Meretukov, New Technologies, 4, 44-48 (2015)

13. P.P. Polskoy, D.R. Mailyan, D.A. Dedukh, S.V. Georgiev, Global journal of Pure and Applied mathematics, 2, 1767-1786 (2016)

14. P.P. Polskoy, S.V. Georgiev, Scientific Review, 10-3, 662-666 (2014)

15. P.P. Polskoy, D.R. Mailyan, S.V. Georgiev, Scientific Review, 12, 496 (2014)

16. P.P. Polskoy, D.R. Mailyan, S.V. Georgiev, Don Engineering Bulletin, 31, 4-1, 138 (2014)

17. P. Polskoy, D. Mailyan, S. Georgiev, V. Muradyan, The strength of compressed structures with CFRP materials reinforcement when exceeding the cross-section size (E3S Web of Conferences) (2018) 
18. P.P. Polskoy, S.V. Georgiev, Scientific Review, 10-2, 411-414 (2014)

19. D.R. Mailyan, P.P. Polskoy, S.V. Georgiev, Scientific Review, 10-3, 667-670 (2014)

20. D.R. Mailyan, P.P. Polskoy, S.V. Georgiev, Scientific Review, 10-2, 415-418 (2014) 